\title{
The controversy surrounding OxyContin abuse: issues and solutions
}

\author{
Sujata S Jayawant \\ Rajesh Balkrishnan² \\ 'University of Houston, Department \\ of Clinical Sciences and \\ Administration, Houston, TX, USA; \\ ${ }^{2}$ Ohio State University College of \\ Pharmacy and School of Public \\ Health, Columbus, $\mathrm{OH}$, USA
}

\begin{abstract}
Absract: This paper overviews the controversies surrounding the abuse of prescription analgesic OxyContin ${ }^{\circledR}$ (oxycodone hydrochloride; Purdue Pharma, Stamford, CT, USA). It discusses solutions to this medication-related issue, which has been touted as reaching epidemic proportions. Relevant literature from 1990 to 2004 was identified through a MEDLINE search, and a thorough internet-based search was conducted to obtain the latest updates and government reports. OxyContin became popular as a street drug through its ability to induce a quick heroinlike euphoria. The media hype surrounding OxyContin abuse and the "black box" warning on its label may have added to the abuse and diversion. The US Food and Drug Administration took steps by writing letters to Purdue Pharma, the manufacturers of OxyContin. Purdue Pharma developed a database to identify OxyContin abusers throughout the nation and also launched campaigns to educate patients through the internet. Further suggestions to managing the abuse of OxyContin include: community pharmacists' assessment of behavioral risk factors that could lead to patient medication abuse; medication abuse risk management courses for physicians; development of a national database linking all pharmacies specifically designed to identify abusers; and tamper-resistant prescription pads for controlled substances, which seems the most plausible and immediate solution to this problem.
\end{abstract}

Keywords: OxyContin, abuse, diversion, prescription drug abuse

\section{Introduction}

According to a government-funded survey, in 1999, an anticipated 4 million Americans aged 12 years or older used oral sedatives, stimulants, antipsychotic agents, or opioids in ways not intended by prescribers (Thompson 2001). A recently available report from the National Household Survey on Drug Abuse suggests that the use of prescription drugs in unintended ways is increasing among adolescents and adults over the age of 60 (Thompson 2001), with analgesics getting most of the attention. Painkiller drugs, especially the opioid analgesics, have a high potential for misuse and abuse. Some of the branded drugs commonly prescribed for the management of chronic pain are OxyContin $^{\circledR}$, Percodan $^{\circledR}$, Percocet $^{\circledR}, \operatorname{Vicodin}^{\circledR}$, Dilaudid $^{\circledR}$, Darvon $^{\circledR}$, and Demerol ${ }^{\circledR}$. The cynosure of attention was Purdue Pharma's OxyContin (Purdue Pharma, Stamford, CT, USA), which was approved by the US Food and Drug Administration (FDA) in 1995 (FDA 2001). The active ingredient of OxyContin is oxycodone, a semisynthetic narcotic analgesic, prescribed for management of moderate to severe pain, chronic pain syndromes, and terminal cancers. The drug is formulated to give a sustained release of oxycodone over a period of 12 hours. Tablets of OxyContin are available in 10-, 20-, 40-, 80-, and 160-mg doses. OxyContin abusers often chew the tablets, crush them and snort the powder, or dissolve them in water and inject the drug for a fast high. According to the US Drug Enforcement Administration (DEA), the prescription painkiller OxyContin may have been involved in 464 overdose-related deaths in two years (Manesses Communication Group 2002). The prevalence of lifetime nonmedical users of oxycodone increased from 11.8 million 
in 2002 to 13.7 million in 2003 (US DHHS 2005). The substantial attention that OxyContin has received is not for its medical effects, but for its addiction liability and abuse potential (Inciardi and Goode 2003). Although much of the talk about OxyContin and its addiction liabilities has been going on for the past few years, the attention turned into a media frenzy when Rush Limbaugh, a radio host, admitted his addiction to the drug on his radio talk show. Soon the headlines of the newspapers and news channels were flooded with news on the abuse of OxyContin. News channels aired special features on the "much talked about" drug.

OxyContin is placed in schedule II of the Controlled Substances Act of 1970. Its placement in schedule II of the Act apparently gave a warning to prescribers and patients using the drug, specifically those who were at a high risk for abuse, that OxyContin is very effective but not without the risk of getting addicted. On the package insert, OxyContin carries a boxed warning that is more commonly known as the infamous "black box". This black box warns users not to use broken tablets, chew, crush, or dissolve the tablets as it may cause rapid release of the drug and even bioavailability of a fatal dose. Hence, before the black box could warn, OxyContin abusers had already found ways to consolidate its mechanism in order to obtain a fast high.

This commentary overviews the controversies surrounding the abuse of drugs like OxyContin and objectively looks at the seriousness of this issue. The mediafrenzy associated with the abuse of OxyContin and gamut of interactions that occurred between the FDA and Purdue Pharma LP are discussed. Abuse of prescription drugs like OxyContin is growing day by day and has been described as a nationwide problem (Thompson 2001). What are the economic aspects of this abuse problem and the financial impact on the healthcare system? Solutions to prevent this drug specific abuse problem are suggested.

\section{Literature review}

An extensive literature review was conducted to find information related to the abuse of prescription drugs like OxyContin. The MEDLINE database was searched for relevant information pertaining to OxyContin from January 1, 1990 to February 12, 2005, and a thorough internet-based search using Google ${ }^{\mathrm{TM}}$ search engine was conducted to obtain the latest updates. The literature review also included different governmental groups and news or reports by Drug Abuse Warning Network (DAWN), National Institute on Drug Abuse (NIDA), National Household Survey on Drug Abuse, and Substance Abuse and Mental Health Services
Administration (SAMHSA). The US Department of Health and Human Services and DEA constituted a considerable proportion of the literature review. Another key source of information was the United States General Accounting Office (GAO) Report of December 2003, which focused on OxyContin abuse and diversion and efforts to address the problem.

\section{Breakthrough versus street drug}

After its approval by the FDA, OxyContin has been hailed as the breakthrough drug in the treatment of moderate to severe pain. It has been heralded as a "miracle drug" as it allows patients with chronic pain to resume a normal life. It is also known as the pharmaceutical heroin as it gives a heroin-like euphoria (US DHHS 2001). Patients with addiction to narcotic analgesics, often present fake complaints to physicians and get prescriptions for OxyContin. The ready availability and efficacy of the drug for analgesia made it popular with patients. Priced at a substantially lower amount than heroin, OxyContin was then recognized as poor man's heroin. The drug became popular not only with patients who were genuinely using it for analgesia, but also with people intending to abuse it. It became known as hillybilly heroin, Oxy, OC, or OxyCotton, and transcended from being a miracle drug used for chronic analgesia to becoming one of the most highly abused drugs. Being a schedule II drug, OxyContin posed a threat with regards to its addiction potential. OxyContin abusers took no time to realize that crushing and injecting or snorting the powdered drug gave a euphoria similar to that of heroin. Since then, cases of abuse or overdose-related deaths have been reportedly increasing.

\section{OxyContin abuse and diversion}

Prescriptions for OxyContin can be easily obtained in clinics by presenting appropriate complaints. Physicians are not formally trained to identify the drug-seeking behavior of abusers (US DHHS 2001). Many patients addicted to the drug often go "doctor-shopping". This is the term coined to describe the phenomenon of patients going to different doctors and obtaining prescriptions for the drug. They also go to different pharmacies in different areas to get those prescriptions filled so that they buy the drug unnoticed. To sustain their habits, OxyContin abusers sometimes engage in committing fraud and theft (US DHHS 2001), and abusers will commit forgery and alter prescriptions. Burglaries and robberies in pharmacies have been reported. Abusers use the drug in unintended ways by crushing the tablets, 
dissolving and injecting, or snorting the powder. In the process of getting a quick heroin-like high, people put themselves at risk of overdose-related death. There have also been case reports of adolescents stealing OxyContin from their parents (Katz and Hays 2004).

The black box warning on the OxyContin package insert recommends that patients do not crush the drug as it results in rapid release of the drug. The warning itself could have encouraged users to use the drug in a manner that is not intended. Also partly responsible for OxyContin's diversion from being an efficacious and convenient analgesic to being an addictive drug are physicians who run OxyContin "pill mills", thereby increasing the availability and accessibility of the prescription analgesic and its potential for abuse.

The DEA's investigation on OxyContin abuse and diversion reports that the primary sources of diverted pharmaceuticals are the illegal acts by physicians and even pharmacists. Some reports allege that physicians have been creating fraudulent prescriptions to provide a supply of the drug for distribution purposes (DEA 2002). Although there has not been any mention about specific data, doctor shopping remains one of the popular ways of illicitly obtaining the prescription drug for abuse (DEA 2002). Robberies, burglaries, and thefts are some of the other methods of obtaining OxyContin illegally.

\section{A national epidemic or media frenzy?}

News about OxyContin abuse first surfaced in rural areas of Maine during the late 1990s and then spread down the east coast to include West Virginia, Kentucky, Southern Ohio. The most hard hit areas were that of the rural Appalachia and Ohio valley (Inciardi and Goode 2003). Data suggest that Kentucky was one of the leading states for OxyContin-related crimes, mostly break-ins (Inciardi and Goode 2003). There was a tremendous increase in the number of patients admitted for treatment of narcotic-related abuse, and the majority of them were being treated for OxyContin. Many reports of OxyContin abuse appeared in the local newspapers and television channels; however, media outlets also reported that the OxyContin abuse problem was not restricted to the rural Appalachia but was spreading across the entire United States.

OxyContin abuse-related news began to appear from as early as 2000. Newspapers ran several features on OxyContin. The Bangor Daily News spread the information including the properties of the drug, the mechanism to compromise the time-release of the drug, tactics used for diversion, and concerns of the medical profession about the potential for abuse (Inciardi and Goode 2003). Media coverage gained more thrust after Kentucky's "Operation OxyFest 2001". Newspaper headlines yelled out different stories about the miracle drug OxyContin and how it was abused. Media coverage included stories about robberies, theft, fraud, pharmacy break-ins, and features of several pill mill doctors who supported the addiction of their patients by frequently prescribing the drug. It appeared as if the OxyContin abuse was transformed from a regional problem to a national epidemic. OxyContin is just one of the drugs of the highly abused list of narcotics that people are addicted to and need more monitoring.

The extensive media coverage and hype made a "villain" out of OxyContin, and there is a concern that the exclusive media focus enhanced the popularity of the drug and contributed towards its abuse.

\section{Economic facets of OxyContin abuse}

The manufacturer of OxyContin, Purdue Pharma LP, was engrossed in aggressively promoting OxyContin, specifically for noncancer pain. The drug has been a major economic success for Purdue Pharma, accounting for almost $80 \%$ of the company's business (Inciardi and Goode 2003). The number of prescriptions and retail sales have been growing at an enormous rate. According to data by IMS, the annual number of prescriptions for OxyContin, for noncancer increased nearly tenfold, from about 670000 in 1997 to about 6.2 million in 2002, whereas the annual number of OxyContin prescriptions for cancer-associated pain grew by fourfold in six years from 250000 to just over 1 million (Katz and Hays 2004). A DEA report indicated that more than 7.2 million prescriptions were dispensed in 2002 and approximately 5.8 million prescriptions were for the single entity product OxyContin. The retail sales of the drug have skyrocketed ever since its market introduction. Recent figures for the drug's retail sales show that there was a $41 \%$ increase in sales from 2000 to 2001 , representing sales worth approximately US $\$ 1.45$ billion (Inciardi and Goode 2003). Retail sales of OxyContin reached nearly US\$1.6 billion in 2002 (ABC World News 2003). In dollar amounts, it is almost the highest in retail sales of brand name substances.

Medicaid fraud presents an inexpensive way of abusing OxyContin. A Medicaid patient would pay US $\$ 3$ for a bottle of a hundred 80-mg OxyContin tablets (Inciardi and Goode 2003). However, in the areas where there is scarcity of 
employment or money, people often sell OxyContin at a very high street price. OxyContin may be sold at US\$1 for each milligram. This diversion has not only prompted burglaries in pharmacies but it has also put a high cost of abuse on its abusers.

\section{FDA takes actions}

Ever since the introduction of OxyContin to the market, it has been the center of attention in the world of chronic pain management. Popular not for its medicinal properties but for its potential for abuse, OxyContin (oxycodone)-related emergency department drug mentions have increased at an alarming rate from 6429 in 1999 to about 18409 in 2001 (DEA nd). Reports of illegal use, misuse, abuse, and diversion of OxyContin prompted the FDA to take immediate actions. The FDA cited Purdue Pharma twice for using potentially false or misleading medical journal advertisements for OxyContin, which violated the Food, Drug and Cosmetic Act 1938. This included one that did not include warnings about the potentially fatal risks associated with the drug's use (US General Accounting Office 2003).

Purdue Pharma had not submitted an OxyContin promotional video for review by the FDA at the time of its initial distribution in 1998, as required by FDA regulations. The FDA in 2002 viewed one such video and found that the video minimized the drug's risks and made unsubstantiated claims (US General Accounting Office 2003).

The FDA also discovered that the safety warning issued to patients through the "black box" may have unintentionally disseminated information that may have led to OxyContin's misuse. In July 2001, the FDA reevaluated OxyContin's label and made changes to strengthen the "Warnings" section. The FDA's most prominent actions were evident from two letters that it wrote to the manufacturers of the drug, but this was not before the drug had nearly become a national crisis.

\section{Purdue Pharma retorts}

Purdue Pharma was highly criticized for its aggressive campaign to promote OxyContin, specifically its targeting of physicians and its failure to submit the promotional video to the FDA. The company responded to the FDA's warnings and actions by releasing a letter that was addressed to all healthcare professionals. The letter specified that the company had revised sections of the prescribing information, specifically the "Warnings" section, which now included a new box warning and an "Indications" section. Purdue Pharma was asked to add a black box warning, which is the highest level of warning the FDA can place on an approved drug product.

To combat criticism, Purdue Pharma distributed more than 400000 brochures on diversion prevention to pharmacists and healthcare professionals and started a pilot program in Maine and Virginia involving free tamperresistant prescription pads for physicians (Thompson 2001). Purdue Pharma submitted its risk management plan to the FDA in August 2001. The plan included actions such as strengthening the safety warning on the label, training Purdue Pharma's sales force on the revised label, conducting comprehensive education programs for healthcare professionals, and developing a national database for identifying and monitoring the abuse and diversion of OxyContin.

Purdue Pharma also developed the Researched Abuse, Diversion, and Addiction-Related Surveillance (RADARS) system, as part of its risk management plan, to study the nature and extent of abuse of OxyContin and other schedule II and III prescription medications and implement interventions to reduce abuse and diversion (US General Accounting Office 2003). RADARS collects and computes abuse, diversion, and addiction rates for certain drugs based on population, and determines national and local trends. As one of the recent efforts to thwart the abuse and misuse of prescription drugs like OxyContin, Purdue Pharma LP, has funded an information clearinghouse for data related to pharmacy thefts called RxPATROL ${ }^{\mathrm{TM}}$ (Pattern Analysis Tracking Robberies and Other Losses). RxPATROL is a collaborative initiative between industry, different pharmacy organizations, and law enforcement to gather, assemble, analyze, and disseminate pharmacy theft intelligence to law enforcement throughout the nation. Purdue Pharma directed its sales representatives to begin using 11 indicators to identify possible abuse and diversion and to report the incidents to Purdue Pharma's General Counsel's Office for investigation. As of September 2003, through its own investigations, Purdue Pharma had identified 39 physicians and other healthcare professionals whom they referred to legal, medical, or regulatory authorities for further action (US General Accounting Office 2003). Purdue Pharma has also disseminated pain-related information to consumers through websites, and it also sponsors 
painfullyobvious.com, which discusses the dangers of abusing prescription drugs.

\section{DEA also on guard}

In response to the growing concern among the local, state, and federal officials about the abuse, illicit use, misuse, and diversion of OxyContin, the DEA has launched a comprehensive effort to prevent this diversion and abuse. Officials in Kentucky are utilizing a new and efficient tool called KASPER (Kentucky All-Schedule Prescription Electronic Reporting), which is a database of all controlled substances dispensed by Kentucky pharmacists (DEA nd).

The action plan has four steps (DEA nd):

1. Enforcement and intelligence. Operations are coordinated to target the individuals and organizations that are involved in abuse or diversion, illegal sale, pharmacy theft, and fraud related to OxyContin.

2. Regulatory and administrative. Authority is utilized to prevent problems. This involves working closely with the FDA and urging the rapid reformulation of OxyContin to an extent that is technically possible.

3. Seeking industry cooperation. The cooperation of Purdue Pharma is sought to make the program a success.

4. Awareness/education/outreach initiatives. Outreach efforts to educate the public, schools, healthcare industry, and state and local governments on the risks associated with OxyContin are implemented.

\section{Discussion}

The findings of this investigation bring up several issues. The use of opioids in pain management has always been an area of debate and of course a lot of concern. But what makes the OxyContin issue so special? The problem lies not only in the specific medication, but in the increasing base rate of addiction in the US and various means of availability of this medication (Passik 2001). Many factors may have contributed to the abuse potential and diversion of OxyContin. The warning on OxyContin's label may have been misleading and inadvertently provoked the nonmedical usage of the drug. To purport their addiction, abusers of OxyContin found out ways to compromise its time-release and certainly different ways to obtain it. Oxycodone being a water soluble ingredient, readily dissolves in water. This property could have provoked abusers to inject a solution of crushed OxyContin tablets to obtain a quick high. Increases in OxyContin-related crime rates can be attributed to the increasing number of abusers. Many reports of OxyContin abuse have occurred in rural areas with laborintensive industries. These industries are often located in economically backward areas. People living in these areas may have been tempted to sell their legitimate prescriptions for profit (Hays 2004). In addition, OxyContin prescriptions are expensive. The generic manufacturing of OxyContin will not begin before the patent expiration of OxyContin in about 2012 (since it was approved in 1995). With a street price of nearly US $\$ 1.00$ per milligram of OxyContin, drug price remains a risk factor for crime related to obtaining the medication. The all-embracing exclusive media coverage and headlines sensationalizing OxyContin abuse also could have added fuel to the fire, but could also have prompted the drug regulating agencies to exercise strict control over controlled prescription substances and also take actions to curb the ongoing abuse.

Purdue Pharma's aggressive promotion of the drug and targeting physicians to increase prescribing and hence sales was received with a lot of criticism. Purdue Pharma was heavily censured for the abuse of OxyContin. On the other hand, the FDA did take mandatory actions against the drug and issued warnings to its manufacturers only after the problem became deep-rooted. Purdue Pharma also took major steps to prevent the abuse and diversion of the drug. In its effort to prevent the OxyContin abuse, Purdue Pharma took steps in every possible direction including addressing healthcare professionals regarding the safe use of OxyContin, strengthening the black box warning, distributing brochures, developing a risk management plan, developing a national database, and also arresting pill mill doctors.

According to their new plan, the FDA, since September 2004, now mandates the drug manufacturers to submit a risk management plan to deal with drug abuse/diversion to obtain the drug approval. Even for the generic manufacturers of the drug, this is a requirement. Preparing beforehand for an expected potential problem such as medication abuse seems to be an important solution to the very problem itself (US General Accounting Office 2003).

Although OxyContin has been abused in many instances, there remain many patients who genuinely use or want to use OxyContin for its medicinal properties, and these patients should not remain untreated. Patients who are in need of the drug are finding it difficult to obtain. Given the controversy, everyone who seems to be using OxyContin could be suspected of abusing it. Pharmacies in some areas 
had stopped carrying OxyContin due to the fear of robberies (Suleman 2002). Patients who had legitimate prescriptions for OxyContin have not been able to obtain the medication on time, and Medicaid patients in several states in the US, namely Florida, Maine, Ohio, South Carolina, and West Virginia, now require prior authorization for OxyContin (Suleman et al 2002). Actions have been taken. Steps have been enforced. But it will take time before this problem mitigates and does not pose a problem to the availability of OxyContin to genuine patients.

Looking at this catastrophe from a pharmacists' perspective affords some insight into preventing a similar situation. In our opinion, the answer lies in educating healthcare providers in addiction and the careful assessment of patients (Passik 2001). Special attention needs to be given to patients' psychological, social, and the many factors that could lead to the risk of abuse. Patients with a history of substance abuse need more focused care, regular and frequent monitoring, and reassessment. There is a shortage of settings that can treat pain and provide an appropriate structure (Passik 2001), whereby the patient's substance abuse history and risk of addiction is carefully assessed and the drug prescribed appropriately. The major players in the community of pain management must address this issue with concern, reason, and education.

A national database linking all pharmacies that is specifically designed to identify abusers can be developed. Community pharmacists can also play a major role in the uprooting of this problem. With the proper assessment of patients and extended counseling sessions, pharmacists can watch out for behavioral factors that might contribute to a potential abuse problem. If necessary, pharmacists should also communicate with the prescribers before dispensing such medication to patients who have a history of illegitimate use and abuse. Physicians could also be educated and encouraged by various physician organizations to undergo specific CME courses addressing issues of risk management for controlled medications. The pharmaceutical industry and various state and federal regulatory agencies should be encouraged to provide the necessary resources for such interventions. The Internet is a good source of dissemination of information about OxyContin, its harmful effects, how to avoid abuse, and how to manage chronic pain. Government and professional organizations also need to accept their share of the responsibility for advocacy, continuing education, and increasing pharmacists' involvement in preventing OxyContin abuse (Cobaugh 2003).
One of the most rational solutions to such a problem would be using tamper-resistant prescription pads for OxyContin. Counterfeit-resistant prescription pads provide prescribers with a rational solution to the growing problem of prescription forgery and prescription drug abuse (see http://www.rxsecurity.com/index.php) (Partners Against Pain 2001). Such prescription pads have copy-resistant background and an individual numeric identifier for each order. When copied, "VOID" appears on the photocopy and tamper-resistant ink shows an attempt to alter the script. Use of such pads would make it nearly impossible to fake prescriptions and the state of Texas in the US encourages their use for controlled substances. It seems most reasonable that the nearest and quickest solution to contain this threat of abuse is using such pads all across the nation.

\section{References}

ABC World News. OxyContin [transcript]. ABC Television, October 17, 2003

Cobaugh DJ. 2003. Pharmacists' role in preventing and treating substance abuse: why are we doing so little? Am J Health Syst Pharm, 60:1947.

[DEA] US Drug Enforcement Administration. 2002 Mar. Drug intelligence brief. Oxycontin: pharmaceutical diversion [online]. Accessed $11 \mathrm{Feb}$ 2005. URL: http://www.usdoj.gov/dea/pubs/intel/02017/02017.html.

[DEA] US Drug Enforcement Administration. nd. DEA statistics [online]. Accessed 12 Mar 2004. URL: http://www.usdoj.gov/dea/ statistics.html.

[DEA] US Drug Enforcement Administration. nd. Action plan to prevent the diversion and abuse of OxyContin [online]. Accessed 12 Mar 2004. URL: http://www.deadiversion.usdoj.gov/drugs_concern/oxycodone/ abuse_oxy.htm.

[FDA] US Food and Drug Administration. 2001. Updates. FDA Consumer, 35(4):3.

Hays LR. 2004. A profile of OxyContin addiction. J Addict Dis, 23:1-9.

Inciardi JA, Goode JL. 2003. OxyContin and prescription drug abuse. Consumers Res Mag, July:17-19.

Katz DA, Hays LR. 2004. Adolescent OxyContin abuse. J Am Acad Child Adolesc Psychiatry, 43:231-4.

Manisses Communication Group. 2002. DEA reports higher rates of OxyContin-related deaths. Alcohol Drug Abuse Wkly, 14:1-2.

Partners Against Pain. 2001. How to stop drug diversion \& protect your pharmacy [online]. Accessed 11 Feb 2005. URL: http://www.partners againstpain.com/index-hs.aspx? sid=18\&aid=7701.

Passik SD. 2001. Responding rationally to recent reports of abuse/diversion of OxyContin. J Pain Symptom Manage, 21:359-60.

Suleman R, Abourjaily H, Rosenberg M. 2002. OxyContin: misuse and abuse. J Mass Dent Soc, 51:56-8.

Thompson CA. 2001. Prescription drug misuse highlighted as national problem. Am J Health Syst Pharm, 58:956.

United States General Accounting Office. 2003. Report to congressional requesters. Prescription drugs. OxyContin abuse and diversion and efforts to address the problem. GAO-04-110. Washington: United States General Accounting Office.

[US DHHS] US Department of Health and Human Services. 2001 Apr. OxyContin: prescription drug abuse. CSAT Advisory, 1(1).

[US DHHS] US Department of Health and Human Services. 2005. The NSDUH report: nonmedical oxycodone users: a comparison with heroin [online]. Accessed 11 Feb 2005. URL: http://www.oas. samhsa.gov/2k4/oxycodoneH/oxycodoneH.htm. 